\title{
Stefano Ballerio, Il romanzo come narrazione e l'autore che racconta
}

\section{Marco Stupazzoni}

\section{Q OpenEdition}

1 Journals

\section{Edizione digitale}

URL: http://journals.openedition.org/studifrancesi/1392

DOI: $10.4000 /$ studifrancesi. 1392

ISSN: 2421-5856

\section{Editore}

Rosenberg \& Sellier

\section{Edizione cartacea}

Data di pubblicazione: 1 décembre 2015

Paginazione: 610

ISSN: 0039-2944

\section{Notizia bibliografica digitale}

Marco Stupazzoni, «Stefano Ballerio, II romanzo come narrazione e l'autore che racconta», Studi Francesi [Online], 177 (LIX | III) | 2015, online dal 01 décembre 2015, consultato il 07 janvier 2021. URL: http:// journals.openedition.org/studifrancesi/1392 ; DOI: https://doi.org/10.4000/studifrancesi. 1392

Questo documento è stato generato automaticamente il 7 janvier 2021.

\section{(c) (i) (9)}

Studi Francesi è distribuita con Licenza Creative Commons Attribuzione - Non commerciale - Non opere derivate 4.0 Internazionale. 


\title{
Stefano Ballerio, Il romanzo come narrazione e l'autore che racconta
}

\author{
Marco Stupazzoni
}

\section{NOTIZIA}

STEFANO BALLERIO, Il romanzo come narrazione e l'autore che racconta, in Sul Conto dell'Autore. Narrazione, scrittura e idee di romanzo, Milano, Franco Angeli, 2013, «Critica letteraria e linguistica», pp. 11-65.

1 Assumendo una prospettiva di indagine dichiaratamente ermeneutica, S. Ballerio analizza, in questo denso primo capitolo del volume, l'idea di romanzo elaborata attraverso gli scritti di Balzac e di W. Scott. Riconsiderando, in modo particolare, l'aspetto della finzionalità e quello delle forme di riferimento alla realtà che gli scrittori presi a modello esprimono attraverso il testo narrativo, l'A. perviene ad un'idea di romanzo come narrazione, nella quale è l'autore che racconta rivolgendosi direttamente al lettore. Gli assunti e le categorie elaborati dalla narratologia strutturalista per definire le istanze produttrici del discorso narrativo (chi racconta è una figura, il narratore extra/omo-diegetico, distinta dalla persona dell'autore) vengono radicalmente messi in discussione da Ballerio nella sua analisi dell'incipit del Père Goriot balzachiano sulla base di una differente prospettiva teorica ed ermeneutica. L'ipotesi formulata dall'A. è che Balzac, proponendo «un'operazione tipica della postmodernità», crea "una figura di narratore che si atteggia ad autore e che tratta da lettori i narratori » (p. 15). La semplice narrazione è messa en abyme e diventa il luogo in cui Balzac «riflette sulla sua opera con i suoi lettori e cerca di agire retoricamente su di loro» (p. 19). Questo presunto dialogo ermeneutico tra Balzac e il lettore si inserisce in un orizzonte storico-letterario ben definito e circoscritto, nel quale autore e lettore sono riconosciuti come soggetti storici portatori di una concezione e di una interpretazione ben precise dell'opera letteraria. Negli orizzonti di Balzac e dei suoi contemporanei, la narrazione è attribuita all'autore e non a un narratore (escludendo i casi in cui la narrazione è affidata ad un personaggio): tra queste due figure, non esiste 
alcuna distinzione e il dialogo ermeneutico tra autore e lettore si realizza in un contesto di realtà a cui essi appartengono e non nel dominio della finzione.

2 Pur nella differente peculiarità del contesto storico e socio-culturale, gli orizzonti di W. Scott e dei suoi lettori sembrano coincidere con quelli che l'A. traccia per Balzac. Anche per l'autore di Waverly, il dialogo ermeneutico avviene nell'ambito del reale e non nel contesto esclusivamente pertinente alla finzione narrativa. L'A. riconosce ai due scrittori una presenza diretta nel testo e la loro legittima funzione di autorevolezza: in Scott, come in Balzac, l'A. rileva «il persistente radicamento dell'enunciazione nella realtà di autore e lettori e insieme lo statuto di verità ancipite che per essa viene rivendicato e riconosciuto, sulla base di una legittimazione autoriale» (p.64). Si tratta di una rivendicazione di autorevolezza che, per quanto rivendicata da entrambi gli scrittori, assume un carattere e una funzione differenti: se W. Scott esibisce la sua maestria nel ricercare, attraverso la memoria e le fonti storiche, il passato nel presente, Balzac vuole accreditarsi come scienziato del suo tempo, come studioso dell'uomo suo contemporaneo appellandosi alla sua conoscenza diretta del mondo ed alle inesauribili facoltà intuitive della sua immaginazione. 